\title{
The possibility of implementation of spent iron catalyst for ammonia synthesis
}

\author{
Ewa A. Ekiert, Rafał Pelka, Krzysztof Lubkowski, Walerian Arabczyk \\ West Pomeranian University of Technology, Institute of Chemical and Environment Engineering, ul. Pulaskiego 10, \\ 70-322 Szczecin, Poland, e-mail: ewa.dabrowa@zut.edu.pl
}

\begin{abstract}
An iron catalyst used in the ammonia synthesis is pyrophoric in its reactive, reduced form. Before further use the catalyst has to be passivated. Results of the research on the iron catalyst - its passivation, re-use as a catalyst in other processes and implementation as a substrate to obtain new nanocrystalline materials have been presented in the paper.
\end{abstract}

Keywords: spent iron catalyst, passivation, carburization.

\section{INTRODUCTION}

Every year plants product over $120 \mathrm{mln}$ tons of ammonium and at the same time they fabricate thousands tons of a spent iron catalyst used in its production. Nowadays the spent catalyst is used as a scrap-iron in a metallurgy industry. Research into utilization of this waste and its bulk reduction are carried on in two different branches. The catalyst could be regenerated through recovery processes and then re-used in the ammonia synthesis. On the other hand, the catalyst still has precious physicochemical properties, despite its deactivation in the ammonia synthesis. Even after the catalyst overheating, which causes sintering and increasing of iron crystallites, it has a nanocrystalline structure with a welldeveloped specific surface area. Therefore the spent iron could be applied as a catalyst in other processes or as a substrate to obtain new nanocrystalline materials.

\section{EXPERIMENTAL}

The investigations were performed over an industrial, spent iron catalyst for the ammonia synthesis, which was unloaded from the ammonia synthesis reactor. Its main parameters were characterized vs the fresh iron catalyst ${ }^{\mathbf{1}, \mathbf{2}}$ : a specific surface area decreased from 12 to $10 \mathrm{~m}^{2} / \mathrm{g}$ and an average Fe crystallites size increased from less than 20 to over $30 \mathrm{~nm}$. The local overheating, which occurs in a catalyst bed, resulted in sintering and recrystallisation of the iron crystallites. The activity of the spent iron catalyst in the ammonia synthesis decreases around $30 \%$.

Kinetics of interactions of the spent iron catalyst with a gaseous phase were carried on with the use of a thermogravimetric method. Characterization of substrates and products was made with an X-ray diffraction, Mössbauer spectroscopy, atomic emission spectroscopy with inductively coupled plasma and temperature programmed reactions, which were described in details elsewhere ${ }^{3,4}$.

The catalyst activity in the ammonia synthesis was expressed as a constant rate in the reaction rate equation. The constant rate was calculated on the basis of modified Temkin - Pyzhev equation shown below:

$r=k \cdot(0,75)^{1,5} \cdot P^{-0,5} \cdot \frac{(1-Z)^{2,5}}{Z} \cdot\left[\frac{Z_{r}^{2}}{\left(1-Z_{r}\right)^{4}}-\frac{Z^{2}}{(1-Z)^{4}}\right]$

where:

$\mathrm{P}$ - pressure of ammonia synthesis,

$\mathrm{Z}$ - mole fraction of ammonia in outlet gasses,
$\mathrm{Z}_{\mathrm{r}}$ - mole fraction of ammonia in equilibrium state.

The activity tests in the ammonia synthesis were performed in the laboratory reactor, at pressure of $10 \mathrm{MPa}^{5}$. The catalysts were reduced in a hydrogen stream, at temperature of $500^{\circ} \mathrm{C}$. After reduction the process of ammonia synthesis started. The fraction of ammonia in outlet gas, necessary for calculation, was measured.

\section{RESULT AND DISCUSSION}

\section{Passivation}

The iron catalyst used in the ammonia synthesis is pyrophoric in its active, metallic form. After being exposed to air it burns and considerable amounts of heat are released. That effect is not only dangerous but it also results in a destruction of a nanocrystalline structure, sintering of the catalyst and a decrease of its activity. The spent iron catalyst has to be passivated before removing from the reactor. Passivation is performed through careful and partial oxidation of the catalyst surface at relatively low temperatures. As a result of the passivation the oxide layer is obtained, which prevents further, deeper oxidation of the catalyst. Its thickness was estimated by different scientists as a value ranged from 1.1 to $3 \mathrm{~nm}^{6-8}$. This discrepancy is an effect of the passivation method used but also of an analytical method used to measured the thickness of the passive layer.

First described attempts of the ammonia catalyst stabilization consisted in nitriding of a reduced catalyst with ammonia9. Unfortunately the material was still pyrophoric. An effective method of passivation was suggested by Temkin and Pyzhev ${ }^{\mathbf{1 0}}$. It consisted in treating the catalyst bed with a mixture of nitrogen and hydrogen comprising small amounts of air $(0.5-1 \%$ vol. $)$, at low temperatures $\left(20-70^{\circ} \mathrm{C}\right)$. The method suggested by Burnett, Allgood and Hall is recommended and commonly used from the early 50's of $20^{\text {th }}$ century till today ${ }^{\mathbf{1 1}}$. According to this method, the catalyst bed is cooled down to temperature of $50-60^{\circ} \mathrm{C}$, then small amounts of air $(0.75-1.2 \%$ vol. $)$ are injected to the nitrogen stream. This method of passivation has also disadvantages: it is time-, energy- consuming and the consumption of nitrogen is also very high. However, the research on the modification of the passivation method or elaboration of a new one were limited only to Russian scientists who described the interaction of an iron catalyst with different oxidizing agents - oxygen, water vapour, carbon dioxide and their mixtures. They discovered that passive layer has a multi-layer struc- 
ture: one oxygen layer is weakly bonded with the catalyst and can be removed with inert gas at temperature close to $150^{\circ} \mathrm{C}$; 2 - 4 layers can be removed at inert gas atmosphere, but at higher temperatures; next $3-6$ layers can be removed only at reduction conditions $\mathbf{1 2}^{\mathbf{1 2}}$. The research into interaction of reduced form of the catalyst with pure air or oxygen showed that at very low $\left(-195--85^{\circ} \mathrm{C}\right)$ or high $(450-$ $500^{\circ} \mathrm{C}$ ) temperatures the catalyst is oxidized to a small degree, typical of the passivation process ${ }^{15-17}$. It was found that the dependence of the iron oxidation degree on temperature at constant oxygen pressure has a bell curve shape. The iron oxidation degree, $\alpha_{\mathrm{Fe}}$, is defined as the ratio of oxygen mass increment at any given moment to the maximum amount of oxygen corresponding to the overall conversion of iron to magnetite. The results of supplementary studies performed in Szczecin University of Technology are shown in Fig.1

The oxidation processes were carried out under atmospheric pressure, at pure oxygen atmosphere, at various temperatures in the range of $300-500^{\circ} \mathrm{C}$, in a differential tube reactor with a thermogravimetric (TG) measurement. Nanocrystalline promoted iron did not reveal the pyrophority under pure oxygen atmosphere at temperatures higher than $300^{\circ} \mathrm{C}$. The oxide layer stable at a given temperature was formed and protected the nanocrystalline iron against further oxidation. The stable oxide layer was composed of an inverse spinel, in which 0.3 of iron ions in the A site of the magnetite structure are substituted by aluminum ions. The formula of the formed spinel was proposed to be $\mathrm{Fe}_{2} \mathrm{AlFe}_{6} \mathrm{O}_{12}{ }^{4}$.

The higher oxidation temperature, the thinner oxide layer covering an every iron crystallite was obtained. Oxide layers formed at high temperatures were stable only at a given temperature, and the temperature decrease under oxygen flow resulted in subsequent oxidation. The oxide layer did not protect the promoted nanocrystalline iron samples against consecutive oxidation under passivation conditions $\left(\mathrm{T}<60^{\circ} \mathrm{C}, \mathrm{p}_{\mathrm{O} 2} \approx 1 \mathrm{kPa}\right)$.

Passivation was performed after the analyzed, reduced sample was cooled down to temperature 100,150 and $180^{\circ} \mathrm{C}$, under the nitrogen flow.
It was found, that the grain diameter did not affect the obtained maximal oxidation degree at a given temperature (Fig. 2). The amount of oxygen gained at $400^{\circ} \mathrm{C}$ corresponds with the oxide layer of $0.56 \mathrm{~nm}$ thickness. At all temperatures the stable state was reached, and the temperature decrease under oxygen flow resulted in subsequent oxidation (the solid line in Fig.1). Considering passivation process, the oxidation degree increased along with increasing of temperature (the dash line in Fig.1).

At the Szczecin University of Technology the research into a new method of passivation of the iron catalyst for ammonia synthesis were performed. One possible suggestion, taking into account that hydrogen in the iron catalyst is bound in three forms, can be implied on the bases of the results presented in Fig.3.

The major quantity of hydrogen is bonded weakly and could be quite easily removed from the catalyst bed. The range of operation temperature of the catalyst bed is from 380 to $510^{\circ} \mathrm{C}$. Reacting gases, hydrogen and ammonia are pumped out of the reactor directly after the ammonia synthesis and before starting the procedure of passivation with oxygen $^{\mathbf{1 8}}$. A decrease of reacting gases pressure prevents a considerable increase of the catalyst bed temperature in the process of typical passivation, which is partly an effect of exothermic catalytic reaction of adsorbed hydrogen with oxygen.

According to another suggestion carbon dioxide was used as the oxidizing agent ${ }^{19}$. Its reaction with iron is endothermic so the increase of the catalyst bed temperature would not occur. After a decrease of the catalyst bed temperature the passivation with classic method as a complementary stage was performed. The relevant conditions of this reaction prevents the arisen of carbon deposit. At temperatures of passivation with $\mathrm{CO}_{2}$ the ratio $p_{\mathrm{CO}} /\left(p_{\mathrm{CO}}+p_{\mathrm{CO}_{2}}\right)$ should not be higher than 0.35 .

\section{Catalyst for carbon nanomaterials formation}

Carbon nanomaterials, especially carbon nanotubes are the subject of many research. There are known many meth-

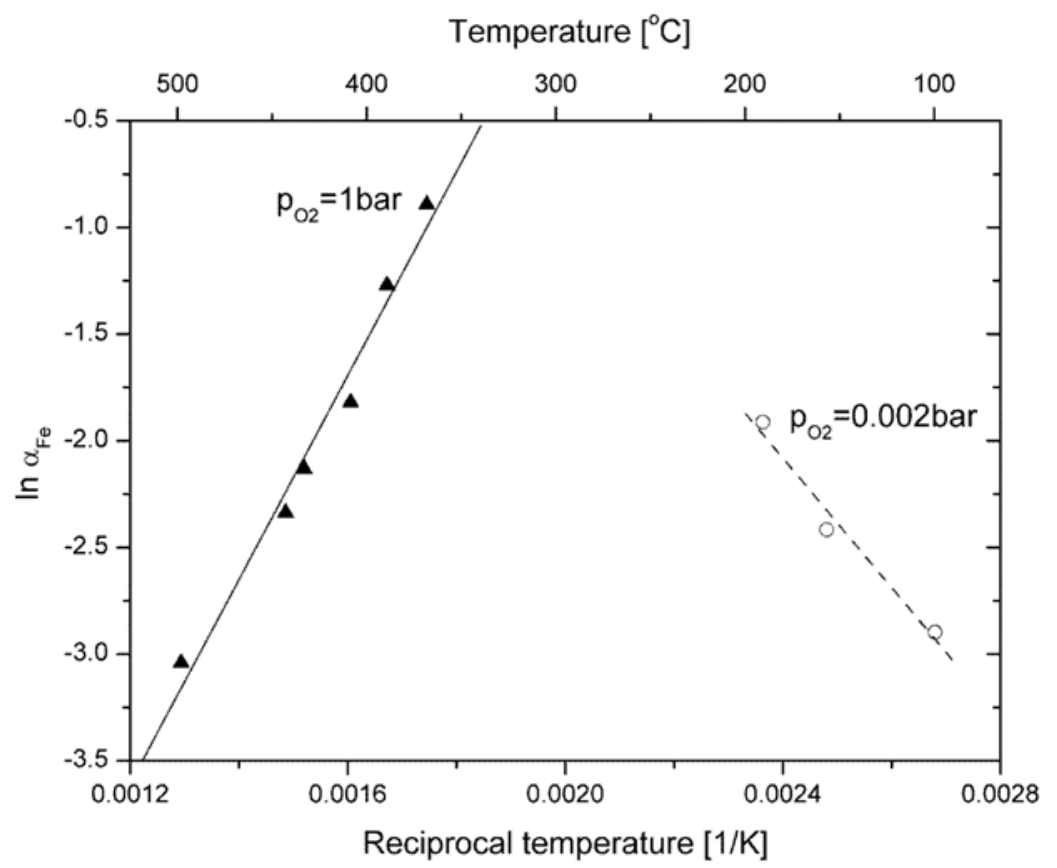

Figure 1. Natural logarithm of the maximum oxidation degree at a given temperature vs. reciprocal temperature for the oxidized (solid line) and passivated (dash line) samples 
ods for their production e.g. conventional ${ }^{20-23}$ and modified arc - discharge ${ }^{\mathbf{2 4}, 25}$, laser pyrolysis ${ }^{\mathbf{2 6}}$. But one of the most simple and inexpensive method is Chemical Vapour Deposition. Catalytic decomposition of hydrocarbons over nanocrystalline iron, cobalt or nickel may be performed at relatively low temperatures in comparison with the earlier mentioned methods. The spent iron catalyst for the ammonia synthesis can be used as a catalyst in a carbon nanomaterials formation according to the CVD method. It leads to the formation of carbon nanofibres, nanotubes and nanocapsules, but also amorphous carbon and nanocrystalline graphite. In order to obtain pure carbon nanomaterials, the two last are the contaminations of the product and have to be eliminated, as well as the catalyst particles. Unnecessary carbon can be removed by oxidation in gaseous phase with pure oxygen or air $^{27-29}$ but also by oxidation in liquid phase with $\mathrm{KMnO}_{4}{ }^{27,30}, \mathrm{H}_{2} \mathrm{O}_{2}{ }^{29,31}, \mathrm{O}_{3}, \mathrm{HClO}_{4}{ }^{29}$. The studies over hydrogenation of amorphous carbon are still performed. It was reported that only hydrogenation at high temperatures provides to purification of carbon nanomaterials ${ }^{32,33}$. How- ever research carried out in our Institute shows that hydrogenation at temperatures approximately equaled to carburization one is satisfactory to remove amorphous carbon from carbon nanomaterials in the presence of the catalyst particles of iron or iron carbide. The results of first carburization and next hydrogenation process are shown in Fig.4.

As a result of a carbon deposit hydrogenation at temperature of $480^{\circ} \mathrm{C}$ a little more than $15 \%$ of pure carbon materials remained in the sample. At the beginning of the hydrogenation curve the rapid decrease of a carbon mass is to be seen. It is correlated with the reduction of iron carbide, which is the least resistant to the hydrogen direct impact. The iron catalyst particles, remained in the sample after hydrogenation can be easily removed by etching with acids.

\section{Iron comppounds embedded in a carbon matrix}

In the carburization process of the iron catalyst, nanocrystalline iron carbide embedded in a carbon matrix is formed. It can be subjected to the process of different iron compounds in a carbon matrix obtaining by simple chemical

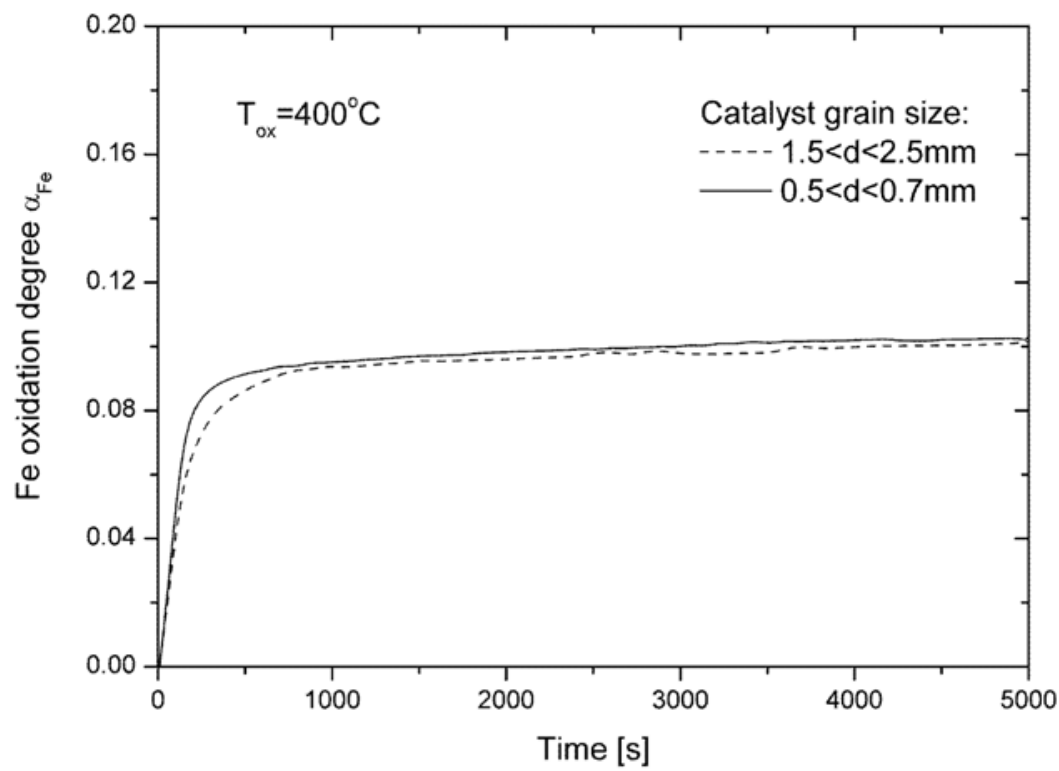

Figure 2. TG curves of the oxidation process of the industrial iron catalyst under oxygen atmosphere at temperature of $400^{\circ} \mathrm{C}$ - different grain diameters

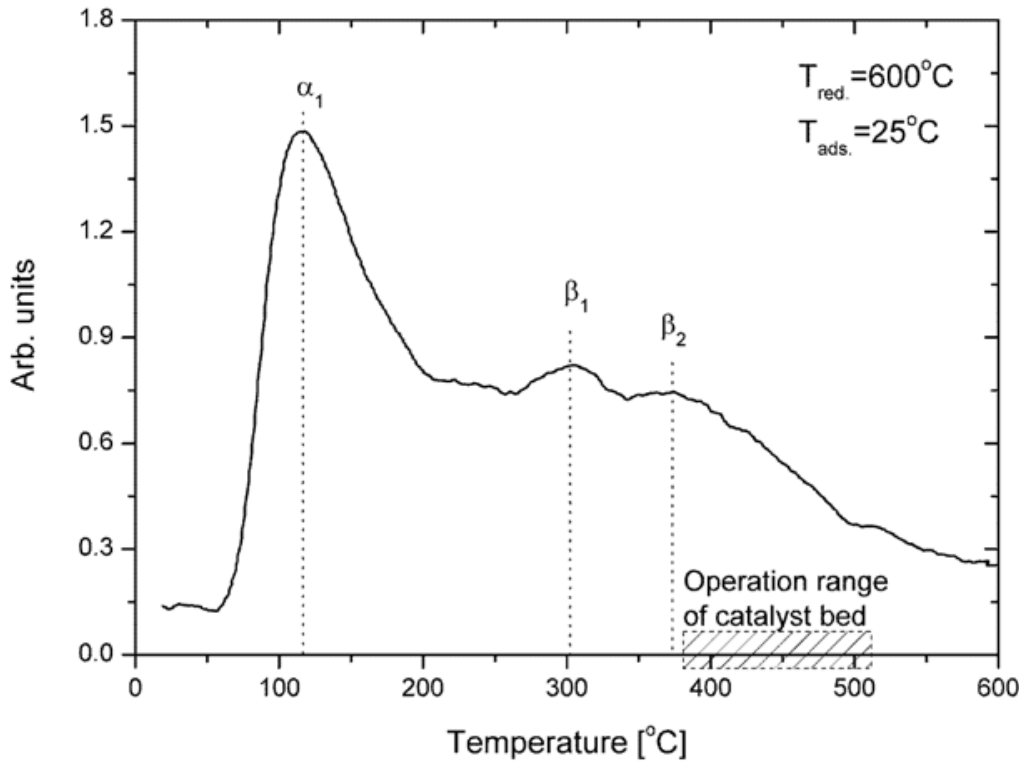

Figure 3. Temperature profile of hydrogen desorption 
reactions ${ }^{34}$. Yet thermal deposition of iron carbide or its low temperature hydrogenation leads to the formation of nanocrystalline iron distributed in a carbon matrix. Using simple oxidizing agents e.g. oxygen, water vapour or carbon dioxide, magnetic and paramagnetic iron oxides embedded in a carbon matrix can be obtained. This system $\mathrm{Fe}-\mathrm{Fe}_{\mathrm{x}} \mathrm{O}_{\mathrm{y}} / \mathrm{C}$ can be used in the iron-steam process, because the oxidation of iron or iron carbide embedded in a carbon matrix with water vapour occurs faster than clean porous iron $^{35}$. Nitriding of iron carbide in a carbon matrix with gaseous ammonia leads to the formation of iron nitride embedded in a carbon matrix.

\section{Regeneration of a spent iron catalyst}

The investigations over recovery processes allowing the re-application of a spent iron catalyst were performed. One of them bases on the regeneration of a catalyst with methods of wet chemistry. A refreshed catalyst was used in the test of activity in ammonia synthesis.

The reaction rate constant directly reflected the activity of iron catalyst in ammonia synthesis. This can be calculated on the basis of following modified Temkin-Pyzhev equation:

$k=V_{m} \cdot\left[-\frac{1}{2}(1-z)^{3.5} \cdot \ln \left(1-\frac{\frac{z^{2}}{(1-z)^{4}}}{\frac{z_{e}^{2}}{\left(1-z_{e}\right)^{4}}}\right)\right]$

where: $V_{m}$-volume flow of inlet gas, $z$ - measured molar fraction of ammonia in the gas mixture, $z_{e}-$ molar fraction of ammonia in equlibrium state under applied conditions.

The Arrhenius plot for the ammonia synthesis on a regenerated and industrial catalyst is shown in Fig. 5.

The catalyst after chemical treatment has the same activity in the ammonia synthesis as an unmodified, fresh catalyst. The apparent activation energy changed slightly and equals $160 \mathrm{~kJ} / \mathrm{mol}$ for the fresh catalyst and $170 \mathrm{~kJ} / \mathrm{mol}$ for the regenerated catalyst.

The fused iron catalyst for the ammonia synthesis has an irregular shape. This is disadvantage because the catalyst grain are diversely packaged in a bed and increase of a flow resistance is observed. The method of obtaining a fused, regular shaped iron catalyst with a simultaneous utilization of a spent catalyst was suggested ${ }^{\mathbf{3 6}}$. In this method the pressing of a catalyst powder was used. Pelleting of the iron catalyst precursor was not possible to perform. The use of binding substances is strictly limited because the iron catalyst is very poison-sensitive, especially with sulfur, chloride and phosphorus compounds. The iron catalyst in a active form can be pressed easily, so after passivation it was added to the catalyst precursor and the mixture was then pressed to obtain pastilles. The activity of this regular shaped catalyst was comparable with the activity of irregular shaped catalyst with the same grain size.

\section{CONCLUSIONS}

The spent iron catalyst for the ammonia synthesis has too precious properties to be utilize only as scrap-iron. It is a valuable source of nanocrystalline iron. The most important and requisitive thing is to correctly passivate the used catalyst before its unloading from the reactor. The investigations performed over the spent iron catalyst proved its possible utilization as a catalyst in the carbon nanomaterials formation, as well as a substrate to obtain pure, nanocrystalline iron carbide, nitride and oxides as well as nanocrystalline iron compounds embedded in a carbon matrix.

\section{ACKNOWLEDGMENT}

The work has been financed as a Research Project No. PBZ-KBN-116/T09/2004 by the Polish Committee for the Scientific Research, Warsaw, Poland.

\section{LITERATURE CITED}

1.Arabczyk, W. \& Jasińska, I. (2004). Studies of the recrystalization process of the iron catalyst for ammonia synthesis. Proceedings of the 13th International Congress on Catalysis 2004, CD-ROM, Book of abstracts: $200-201$.

2. Jasińska, I. (2004). The verification of the model of active surface of ammonia synthesis catalyst. Unpublished

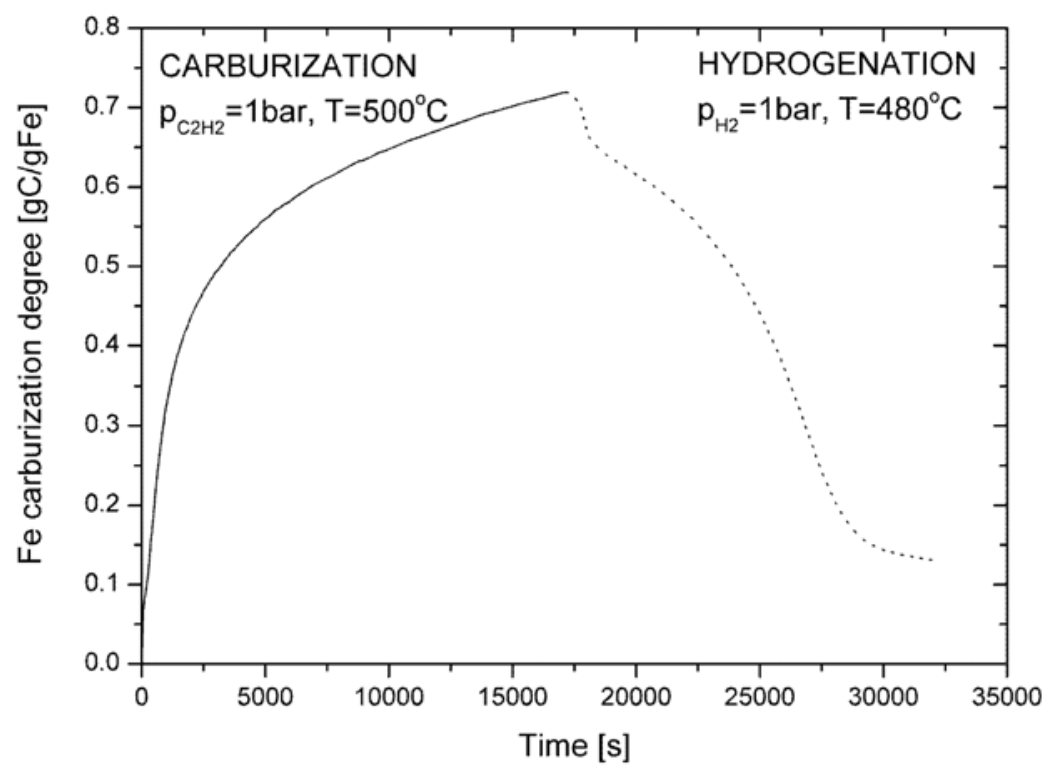

Figure 4. Thermogravimetric curves of carburization with ethane at $500 \mathrm{oC}$ of iron catalyst and hydrogenation at $480^{\circ} \mathrm{C}$ of carbon deposit 
doctoral dissertation, Szczecin University of Technology, Szczecin, Poland.

3.Arabczyk, W. \& Jasińska, I. (2006). The current state of knowledge of iron catalysts used in ammonia synthesis. Przem.Chem. 85/2, 130 - 137.

4. Pelka, R., Pattek-Janczyk, A. \& Arabczyk, W. (2008). Studies of the oxidation of nanocrystalline iron with oxygen by means of TG, MS, and XRD methods. J. Phys. Chem. C, 112, 13992 - 13996. DOI:10.1021/jp710163h.

5. Kałucki, K., Arabczyk, W., Narkiewicz, U. \& Śpiewak, Z. (1994). Industrial catalyst for ammonia syntheis with higher thermal resistance. Przem. Chem., 73/5, $174-175$.

6. Barański, A., Pattek, A. \& Reizer, A. (1978). Determination of the passivation layer thickness in iron catalysts for the ammonia synthesis. Bull. Acad. Polon. Sci. Ser. Sci. Chim., $26353-358$.

7. Lubkowski, K., Arabczyk, W., Grzmil, B., Michalkiewicz, B. \& Pattek-Jańczyk, A. (2007). Passivation and oxidation of an ammonia iron catalyst. Appl. Catal. A, 329, $137-147$. DOI:10.1016/j.apcata.2007.07.006.

8. Chudinov, M.G., Minaev, D.M. , Zaichko, G.N. \& Alekseev, A.M. (1984). Study of the surface state and thichkness of oxide layer of dispersed iron promoted by potassium and aluminium oxides by $\mathrm{X}$-ray photoelektron spectroscopy. Kinet. Katal. 25, 1205 - 1208.

9. Khrizman, I.A. (1940). Stabilization of reduced catalyst for ammonia synthesis. Ber. Inst. Phys. Chem., Akad.Wiss.Ukr.S.S.R., 12, 15 - 20.

10. Temkin, M. \& Pyzhev, V.M. ().USSR Patent No. 64607.

11. Burnett, J.A., Allgood, H.Y. \& Hall, J.R. (1953). Stabilization of ammonia syntheisis catalyst. Ind. Eng. Chem., 45, $1678-1682$.

12. Krylova, A.V. , Morozov, V.V., Lachinov, S.S. \& Torocheshnikov, N.S. (1978). Oxygen sorption and thermal regeneration of sorption centers on catalysts of ammonia synthesis in helium and hydrogen flow. React. Kinet. Catal. Lett., 9, 125 - 130.

13. Tsarev, V.I., Aptekar, E.L., Krylova, A.V. \& Torocheshnikov, N.S. (1980). Adsorption microcalometric studies of the interaction between oxygen and an industrial ammonia synthesis catalyst. React. Kinet. Catal. Lett,. 14, 279 -282 .

14. Vasilevich, A.A., Blokhina, L.N., Chesnokova, R.V. \& Minayev, D.M. (1988). Oxygen sorption on reduced iron catalysts with different content of promoters. React. Kinet. Catal. Lett., 36, 467 - 471.

15. Krylova, A.V., Ustimenko, G.A. \& Torocheshnikov, N.S. (1982). Preparation of non-pyrophoric metallic catalysts. Stud. Surf. Sci. Catal., 16, 441 - 450.

16. Krylova, A.V., Tsarev, V.I., Peev, T.M., Kushnarenko, T.I. \& Torocheshnikov, N.S. (1986).Interactions between catalysts for ammonia synthesis and oxygen. React. Kinet. Catal. Lett., 30, 229 - 235.

17. Krylova, A.V., Ustomenko, G.A., Nefedova, N.V., Peev, T.M. \& Torocheshnikov, N.S. (1986). Effective routes of stabilization of pyrophoric industrial catalysts. Appl. Catal., 20, 205 - 213. DOI:10.1016/0166-9834(86)80016-1.

18. Arabczyk, W., Pelka, R. \& Arabczyk, M. (2006). Pol. Pat. No. 381907

19. Arabczyk, W. \& Ekiert, E. (2006). Pol. Pat. No. 381201

20. McHenry, M.E., Majetich, S.A., Artman, J.O., DeGraef, M. \& Staley, S.W. (1994). Superparamagnetism in carboncoated Co particles produced by the Kratschmer carbon arc process. Phys. Rev. B, 49, 11358 - 11363. DOI:10.1103/ PhysRevB.49.11358.

21. Saito, Y., Yoshikawa, T., Okuda, M. \& Fujimoto, N. (1994). Cobalt particles wrapped in graphitic carbon prepared by an arc discharge method. J. Appl. Phys,. 75, 134 137. DOI:10.1063/1.355901

22. Yoshida, Y., Shida, S., Ohsuna, T. \& Shiraga, N. (1994). Synthesis, identification, and growth mechanism of $\mathrm{Fe}, \mathrm{Ni}$, and Co crystals encapsulated in multiwalled carbon nanocages. J. Appl. Phys., 76, 4533-4539. DOI:10.1063/ 1.358446 .

23. Setlur, A.A., Dai, J.Y., Lauerhaas, J.M. \& Chang, R.P.H. (1998). Formation of filled carbon nanotubes and nanoparticles using polycyclic aromatic hydrocarbon molecules. Carbon, 36, 721 - 723. DOI:10.1016/S00086223(98)00044-X.

24. Dravid, V.P., Host, J.J., Teng, M.H., Elliott, B,. Hwang, J., Johnson, D.L., Mason, T.O. \& Weertman, J.R. (1995). Controlled-size nanocapsules. Nature, 374, 602. DOI:10.1038/ $374602 \mathrm{a} 0$.

25. Jiao, J., Seraphin, S., Wang, X. \& Withers, J.C. (1996). Preparation and properties of ferromagnetic carbon-coated Fe, Co, and Ni nanoparticles. J. Appl. Phys., 80, $103-108$. DOI:10.1063/1.362765

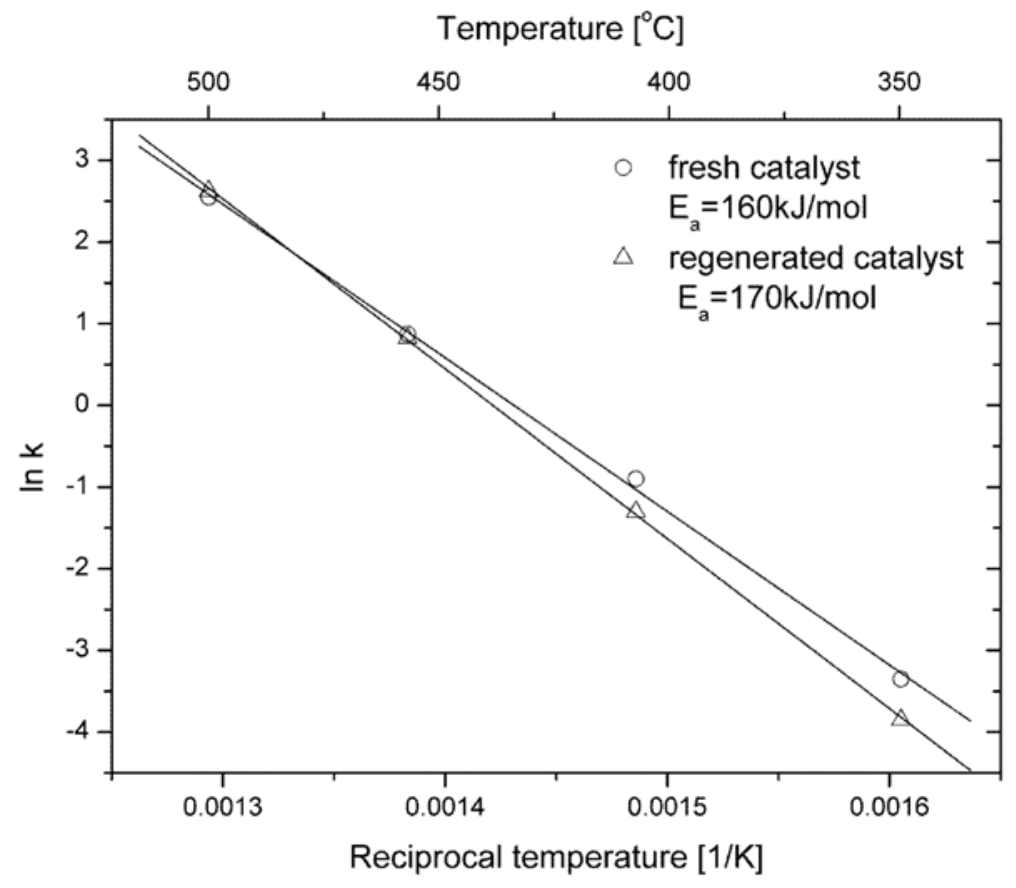

Figure 5. The Arrhenius dependence for fresh and regenerated iron catalyst for the ammonia synthesis 
26. Alexandrescu, R., Morjan, I., Dumitrache, F., Birjega, R., Jaeger, C., Mutschke, H., Soare, I., Gavrila-Florescu, L. \& Ciupina, V. (2007). Structural characteristics of Fe3Cbased nanomaterials prepared by laser pyrolysis from different gas-phase precursors. Materials Science and Engineering C, 27, 1181 - 1184. DOI:10.1016/j.msec.2006.07.008

27. Moon, J.-M., An, K.H., Lee, Y.H., Park, Y.S., Bae, D. J. \& Park, G. -S. (2001). High-Yield Purification Process of Singlewalled Carbon Nanotubes. J. Phys. Chem. B, 105, 56775681. DOI:10.1021/jp0102365.

28. Colomer, J.-F., Piedigrosso, P., Fonseca, A. \& Nagy, J.B. (1999). Different purification methods of carbon nanotubes produced by catalytic synthesis. Synth. Met., 103, 2482 - 2483. DOI:10.1016/S0379-6779(98)01066-2.

29. Tohji, K., Takahashi, H., Shinoda, Y., Jeyadevan, B., Matsuoka, I., Saito, Y., Kasuya, A., Ito, S. \& Nishina, Y. (1997). Purification procedure for single-walled nanotubes. J. Phys. Chem. B, 101, 1974-1978. DOI:10.1021/jp962888c.

30. Hernadi, K., Siska, A., Thien-Nga, L., Forró, L. \& Kiricsi, I. (2001). Reactivity of different kinds of carbon during oxidative purification of catalytically prepared carbon nanotubes. Solid State Ionics, 141, 203 - 209. DOI:10.1016/ S0167-2738(01)00789-5.

31. Ando, Y., Zhao, X., Inoue, S. \& Iijima, S. (2002). Mass production of multiwalled carbon nanotubes by hydrogen arc discharge. J. Cryst. Growth, 237 - 239, 1926 - 1930. DOI:10.1016/S0022-0248(01)02248-5.

32. Morishita, K. \& Takarada, T. (1999). Scanning electron microscope observation of the purification behaviour of carbon nanotubes. J. Mater. Sci., 34, 1169 - 1174. DOI:10.1023/ A: 1004544503055 .

33. Ivanov, V., Fonseca, A., Nagy, J.B., Lucas, A., Lambin, P., Bernaerts, D. \& Zhang, X.B. (1995). Catalytic production and purification of nanotubules having fullerene-scale diameters. Carbon, 33, 1727 - 1738. DOI:10.1016/00086223(95)00132-1.

34. Arabczyk, W., Narkiewicz, U., Pełech, I., Podsiadły, M., Ekiert, E. \& Pelka, R. (2007). Pol. Patent No. 384781.

35. Arabczyk, W. \& Ekiert, E. (2008). Pol. Pat. No. 386622. 36. Arabczyk, W. \& Ekiert, E. (2008). Pol. Pat. No. 386623. 